\title{
Análise do binômio tempo e temperatura de preparações à espera para distribuição em um restaurante universitário
}

\author{
Analysis of time-temperature control of preparations \\ waiting for distribution at university restaurant
}

Thainá Peixoto', Angélica Cotta Lobo Leite Carneiro², Leandro Cardoso²

'Universidade Federal de Ouro Preto

2Universidade Federal de Juiz de Fora

Contato: Thainá Peixoto - thainagomespeixoto@gmail.com

\begin{abstract}
Resumo
Analisar a adequação do binômio tempo e temperatura de preparações quentes e frias prontas para consumo à espera para distribuição em um restaurante universitário. Foram aferidas as temperaturas de preparações frias em seis dias de abril e quentes em seis dias de julho em um Restaurante Universitário. A primeira aferição de cada preparação ocorreu imediatamente após o preparo, e a partir desse momento, realizaram-se aferições a cada hora. Foram avaliadas 35 preparações quentes e 18 preparações frias. A preparação quente com maior adequação ao binômio tempo e temperatura foi o feijão e a com menor adequação foi a opção vegetariana. Todas as saladas de legumes cozidos apresentaram temperaturas inadequadas para consumo. Todas as saladas de folhosos e legumes crus apresentaram temperaturas acima de $21^{\circ} \mathrm{C}$ ou não respeitaram o binômio. $\mathrm{A}$ maioria das preparações analisadas apresentaram temperaturas inadequadas, indicando a necessidade de adoção de medidas para maior controle do binômio tempo e temperatura, garantindo a segurança dos alimentos oferecidos aos comensais.
\end{abstract}

Palavras-chave: Higiene dos Alimentos. Microbiologia de Alimentos. Inocuidade dos Alimentos.

\begin{abstract}
To analyze the suitability of the time-temperature control of hot and cold preparations waiting for distribution at a University Restaurant. The temperatures of cold preparations were evaluated in April and hot preparations in July at University Restaurant. The first measurement in each preparation occurred immediately after being cooked, and from that moment, hourly measurements were taken. The hot and cold preparations that were evaluated comprised 35 and 18, respectively. The hot preparation with the best adequate time-temperature control was beans and the least suitable was the vegetarian option. Cooked vegetable salads were inadequate for consumption. The fresh leafy salads and raw vegetables had a temperature above $27^{\circ} \mathrm{C}$ or did not respect the binomial. The results of analysis of time-temperature control found in the restaurant showed that most of the preparations had inadequate temperatures, being necessary
\end{abstract}


implementation of more effective techniques for time-temperature control, ensuring the safety of the food offered to diners.

Keywords: Food Hygiene. Food Microbiology. Food Safety.

\section{INTRODUÇÃO}

A universidade como instituição pública de ensino superior, deve cumprir seu papel na assistência estudantil, provendo meios para auxiliar na permanência de seus estudantes e o desenvolvimento adequado de seus estudos ${ }^{1}$. Um destes meios consiste no fornecimento de alimentação adequada em quantidade e qualidade. Nesse sentido, os Restaurantes Universitários (RU) possuem um papel fundamental para a promoção da saúde e desempenho acadêmico dos estudantes, uma vez que fornecem refeições nutricionalmente equilibradas ${ }^{2,3}$. Além disso, os RU também contribuem para a manutenção de alguns estudantes na universidade, uma vez que muitos não teriam condições financeiras de se alimentar, o que poderia comprometer a adesão aos estudos $^{1,3}$. Além dos estudantes, os RU também podem atender os servidores da própria instituição de ensino, podendo alcançar um grande número de pessoas.

Para além da alimentação adequada nutricionalmente, os RU precisam atender aspectos relacionados ao controle higiênico-sanitário, à qualidade sensorial das refeições ofertadas e à estrutura física ${ }^{3}$. Nesse contexto, o controle higiênicosanitário merece destaque, uma vez que o aumento da demanda pela alimentação fora de casa pode sobrecarregar os serviços de alimentação, gerando impactos negativos nos estabelecimentos que não conseguirem se adequar a esse volume ${ }^{4}$. Essa situação pode provocar a contaminação dos alimentos, causando danos à saúde humana, como as doenças veiculadas por alimentos (DVA) ${ }^{5,6}$. Entre 2000 e 2017, os restaurantes e padarias foram responsáveis por 15,2\% das ocorrências de surtos de DVA no Brasil, ficando atrás apenas das ocorrências em residências.

Os fatores que mais contribuem para o risco de danos ao consumidor estão associados à contaminação dos alimentos provocada pelo descumprimento das boas práticas de manipulação ${ }^{8}$. Essas, por sua vez, possuem relação direta com o correto manuseio das matérias-primas, a higienização das instalações, equipamentos e utensílios, a higiene pessoal dos manipuladores envolvidos nas etapas de produção dos alimentos e com o controle de pragas e vetores ${ }^{9}$. 
Os perigos microbiológicos, representados por micro-organismos, como fungos e bactérias, representam a principal fonte de contaminação de alimentos e os utensílios utilizados nas etapas de preparo, assim como os manipuladores envolvidos nessas etapas, são os principais veículos de contaminação. Além disso, a contaminação cruzada, ou seja, aquela que ocorre com a transferência de microorganismos dos alimentos não higienizados para alimentos já prontos para consumo, se configura um importante risco de contaminação de alimentos, muito comum em Unidades de Alimentação e Nutrição (UAN) ${ }^{10,11,12}$.

A sobrevivência, crescimento e consequente proliferação dos micro-organismos em um alimento dependem de diversos fatores intrínsecos e extrínsecos a ele. Dentre os fatores extrínsecos, a temperatura se destaca por ser determinante para o crescimento microbiológico. Todo micro-organismo possui uma faixa de temperatura necessária para sua sobrevivência e uma outra faixa, mais restrita, de temperatura ótima para seu pleno desenvolvimento ${ }^{13}$. A faixa de temperatura ideal para o crescimento microbiano varia de 10 a $65^{\circ} \mathrm{C}$, dependendo do micro-organismo ${ }^{14}$.

Em faixas ideais de temperatura, o crescimento microbiano e o início da multiplicação podem ocorrer de maneira muito rápida. Diante disso, uma das formas mais indicadas na literatura de se evitar o crescimento e consequente proliferação microbiana é por meio do controle do binômio tempo e temperatura, pelo qual se faz o monitoramento da temperatura e o acompanhamento do tempo em que o alimento se encontra sob aquela temperatura ${ }^{13}$. Buscando reduzir os surtos por DVA e considerando os fatores favoráveis para contaminações microbiológicas dos alimentos, algumas legislações, como a Resolução de Diretoria Colegiada (RDC) 216/2004 ${ }^{15}$ da Agência Nacional de Vigilância Sanitária (ANVISA) e o Centro de Vigilância Sanitária de São Paulo, através da CVS 5/2013 ${ }^{16}$ determinam os binômios tempo e temperatura para cada tipo de preparação.

Em alguns estudos que investigaram o binômio tempo e temperatura de refeições ${ }^{12,18,19}$ foram observadas inadequações na manutenção desse binômio. Entretanto, apenas um destes estudos investigou a relação tempo e temperatura de preparações à espera para a distribuição ${ }^{20}$. A maioria dos estudos investigou tal relação no momento da distribuição de refeições ${ }^{12,18,19}$.

Dessa forma, considerando o cenário apresentado em relação as DVA e a importância do binômio tempo e temperatura para garantia da segurança dos alimentos, o objetivo deste estudo foi analisar a adequação do binômio tempo e temperatura de 
preparações prontas para consumo à espera para distribuição, em um restaurante universitário. Espera-se com esse estudo contribuir para melhorias não só dos processos de controle e monitoramento de temperaturas em UAN, como também para as pesquisas da área de higiene de alimentos, na busca permanente da segurança dos alimentos oferecidos aos comensais.

\section{MÉTODO}

\section{Caracterização}

Trata-se de um estudo transversal realizado em duas unidades de um RU localizado em uma cidade do leste de Minas Gerais, Brasil. O RU possuía três nutricionistas e uma técnica em nutrição responsável pela produção média de 1500 refeições diárias, sendo 1200 no almoço e 300 refeições no jantar. O RU possuía duas unidades, na A se produzia e distribuía refeições no almoço (900 refeições) e no jantar (300 refeições). Na unidade B não havia produção de refeição e sim apenas a distribuição daquelas que eram produzidas e transportadas da unidade $\mathrm{A}$, totalizando o fornecimento, em média, de 300 refeições/dia apenas no horário do almoço. O cardápio da UAN era classificado como opcional (padrão tipo B), sendo composto por dois tipos de arroz, um tipo de feijão, uma guarnição, um prato principal, uma opção vegetariana e três tipos de saladas, além de sobremesa e suco.

O armazenamento das preparações prontas para consumo era realizado em utensílios de inox, também chamados de gastronorms (GN), de variadas profundidades, sendo as mais utilizadas nas unidades: 200mm (1/1), 150mm (1/1), $100 \mathrm{~mm}(1 / 1), 200 \mathrm{~mm}(1 / 2), 150 \mathrm{~mm}(1 / 2), 100 \mathrm{~mm}(1 / 2)$ e $65 \mathrm{~mm}(1 / 2)$. As GN distribuídas na unidade A eram armazenadas em um carro térmico aquecido, para as preparações quentes, e em um pass through refrigerado, para as preparações frias, até o momento da sua distribuição.

Pelo fato de se transportar as refeições da unidade A para a B, as GN destinadas à unidade B eram armazenadas em equipamentos exclusivos, adaptados com rodas para facilitar a locomoção. Assim como as GN distribuídas na unidade A, as preparações quentes transportadas para a unidade $B$ eram acondicionadas em um carro térmico aquecido. As preparações frias eram acondicionadas em um freezer horizontal. Próximo ao horário de saída do veículo da unidade A para a B, os equipamentos (carro térmico e freezer) eram desligados da energia e acomodados no veículo de transporte, onde permaneciam desligados até a chegada à unidade $\mathrm{B}$, quando eram retirados do 
veículo, posicionados em um local próximo ao balcão de distribuição e novamente ligados na energia elétrica. Esses equipamentos permaneciam desligados em torno de 45 minutos durante o transporte da unidade A para a B.

A distribuição acontecia nas duas unidades com sistema bilateral com balcão térmico aquecido por banho-maria e balcão térmico resfriado por pista refrigerada. Todas as preparações ficavam prontas em média às 8 horas e 30 minutos. 0 horário de distribuição do almoço nas duas unidades era das 10 horas e 45 minutos às 13 horas e 45 minutos.

\section{Coleta de Dados}

Para a coleta de dados, foi elaborada uma planilha para preparações frias e uma para preparações quentes com auxílio do Microsoft Excel ${ }^{\circledR}$ versão 2016, contendo o horário da aferição da temperatura, a categoria da preparação analisada, a temperatura aferida e um espaço para possíveis observações.

As temperaturas de preparações frias foram coletadas em seis dias de abril, sendo três dias na unidade A e três dias na unidade B. As temperaturas das preparações quentes foram aferidas em seis dias de julho, da mesma forma que as preparações frias, ocorrendo em três dias na unidade A e três dias na unidade B. Essa temperatura foi coletada, em todos os casos, durante o período de armazenamento da preparação, enquanto esperava para ser distribuída, no horário do almoço.

As preparações frias analisadas incluíram diferentes tipos de saladas que foram agrupadas em três categorias: salada de legumes crus, salada de folhosos e salada de legumes cozidos. As preparações quentes analisadas incluíram os acompanhamentos (arroz branco, arroz integral e feijão), guarnição, prato principal e opção vegetariana.

A temperatura das preparações frias foi aferida utilizando um termômetro digital do tipo espeto da marca Inconterm ${ }^{\circledR}$. Para as preparações quentes da unidade $B$, utilizou-se um termômetro TFA Dostmann ${ }^{\circledR}$ nos três dias de aferição. As preparações quentes da unidade A foram avaliadas com o termômetro Inconterm ${ }^{\circledR}$.

Para aferir a temperatura das preparações, a porta do equipamento foi aberta, a GN destampada e a haste do termômetro inserido no centro geométrico da preparação a ser analisada e que já estava porcionada na GN, à espera da distribuição. Assim que a temperatura aparecesse de forma estável no visor do termômetro, era registrada. 
Foram realizados procedimentos de higienização do termômetro com álcool 70\% antes e após cada aferição.

A primeira aferição de temperatura das preparações ocorreu imediatamente após o preparo, logo após serem porcionadas nas GN e acondicionadas no equipamento de destino. A partir desse momento, as outras cinco aferições foram realizadas a cada hora.

\section{Análise de Dados}

Os dados coletados foram tabulados em planilhas no programa Microsoft Excel ${ }^{\circledR}$ versão 2016. Após análise, as temperaturas de cada preparação foram alocadas em gráficos com tempo. Além disso, a frequência de adequação ao binômio tempo e temperatura também foi calculada para cada preparação.

Para as preparações frias, adotou-se como referência o Manual da ABERC ${ }^{21} \mathrm{em}$ função da ausência de valores preconizados para saladas frias na RDC 216/2004 ${ }^{15}$. Ressalta-se que ABERC ${ }^{21}$ utiliza como base a Resolução de Diretoria Colegiada 216/2004 ${ }^{15}$ e a legislação do Centro de Vigilância Sanitária $5 / 2013^{16}$ para gerar seu conteúdo e conta com profissionais de renome no que tange a segurança dos alimentos. Os parâmetros adotados foram: preparações frias abaixo de $10^{\circ} \mathrm{C}$ podem ser armazenadas, distribuídas e consumidas por até quatro horas; entre $10^{\circ} \mathrm{C}$ e $21^{\circ} \mathrm{C}$ esse tempo reduz para duas horas. Para alimentos que sofreram cocção, mas serão servidos frios, como as saladas cozidas, o preconizado é uma redução inicial da temperatura até $10^{\circ} \mathrm{C} \mathrm{em}$ menos de duas horas, com posterior armazenamento a $4^{\circ} \mathrm{C}$ por no máximo cinco dias.

Para as preparações quentes foi usada como referência a RDC 216/2004 ${ }^{15}$ e o estabelecido por $\mathrm{ABERC}^{21}$, uma vez que a RDC 216/2004 ${ }^{15}$ não especifica o binômio tempo e temperatura para preparações quentes que se encontrem abaixo de $60^{\circ} \mathrm{C} . \mathrm{O}$ binômio tempo e temperatura adotado como referência nesse estudo foi: preparações acima de $60^{\circ} \mathrm{C}$ podem ser armazenadas, distribuídas e consumidas em até seis horas; abaixo de $60^{\circ} \mathrm{C}$, até uma hora.

\section{RESULTADOS}

\section{Preparações Quentes}

Foram aferidas as temperaturas de 35 preparações quentes, sendo seis de arroz branco, seis de arroz integral, seis de feijão, seis de pratos principais e seis de opções vegetarianas. Das guarnições foram aferidas as temperaturas de apenas cinco 
preparações porque uma delas não foi armazenada nos equipamentos de espera. Das preparações avaliadas, $65,7 \%$ estiveram acima de $60^{\circ} \mathrm{C}$ por até seis horas, apresentando tempo e temperatura adequados. O restante $(34,3 \%)$ se apresentou abaixo de $60^{\circ} \mathrm{C}$ por mais de uma hora, que seria o limite máximo permitido, estando inadequadas para consumo após esse período. Nenhuma preparação esteve acima de $60^{\circ} \mathrm{C}$ por mais de seis horas, da mesma forma que nenhuma preparação esteve abaixo de $60^{\circ} \mathrm{C}$ por menos de uma hora (Figuras 1 e 2 ).

O arroz branco e integral apresentaram 83,0\% de adequação ao binômio tempo e temperatura (Figura 1 A e B). Todas as preparações de feijão também atenderam ao binômio tempo e temperatura (Figura $1 \mathrm{C}$ ).

Das guarnições, 60,0\% respeitaram o binômio tempo e temperatura, sendo que das inadequadas $(40,0 \%)$ uma preparação havia sido acondicionada abaixo de $60^{\circ} \mathrm{C}$ e foi retirada para o balcão térmico antes do fim das aferições. Outra preparação permaneceu abaixo de $60^{\circ} \mathrm{C}$ por mais de 1 hora (Figura 1D). Além disso, observa-se uma inconstância na variação de temperatura das guarnições, uma vez que cada preparação se comportou de uma forma diferente, normalmente com grande variação nas temperaturas.

Figura 1 - Binômio tempo e temperatura de preparações quentes na unidade A e unidade B. (A) Arroz branco; (B) Arroz integral; (C) Feijão; (D) Guarnição.
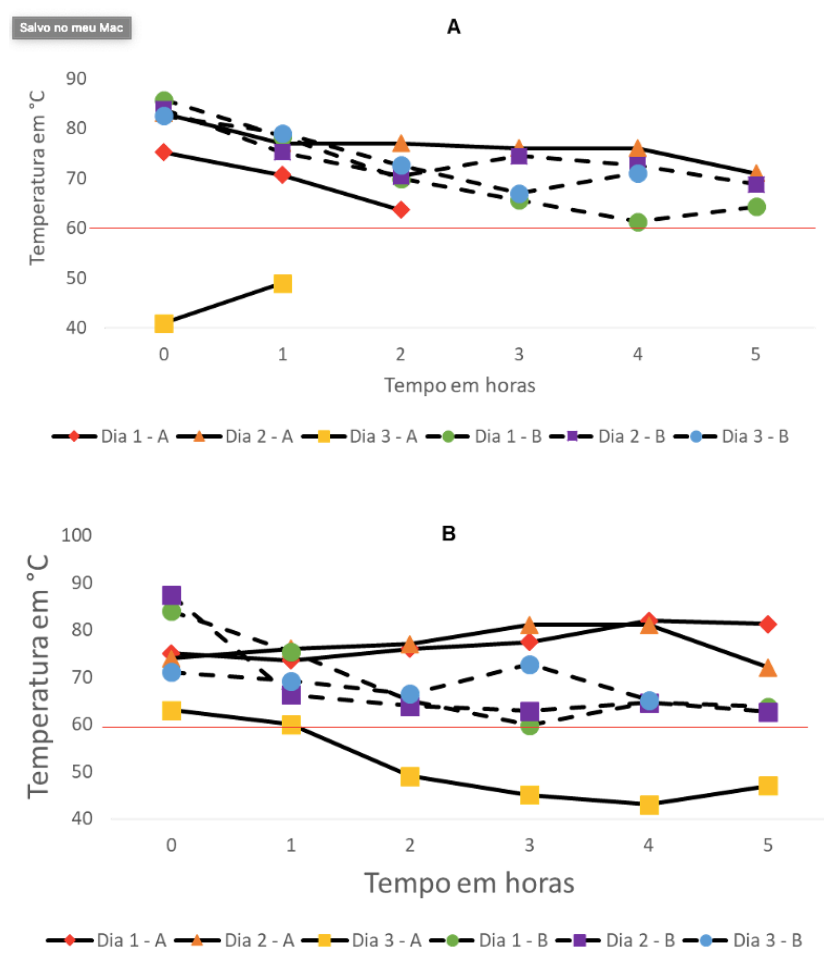

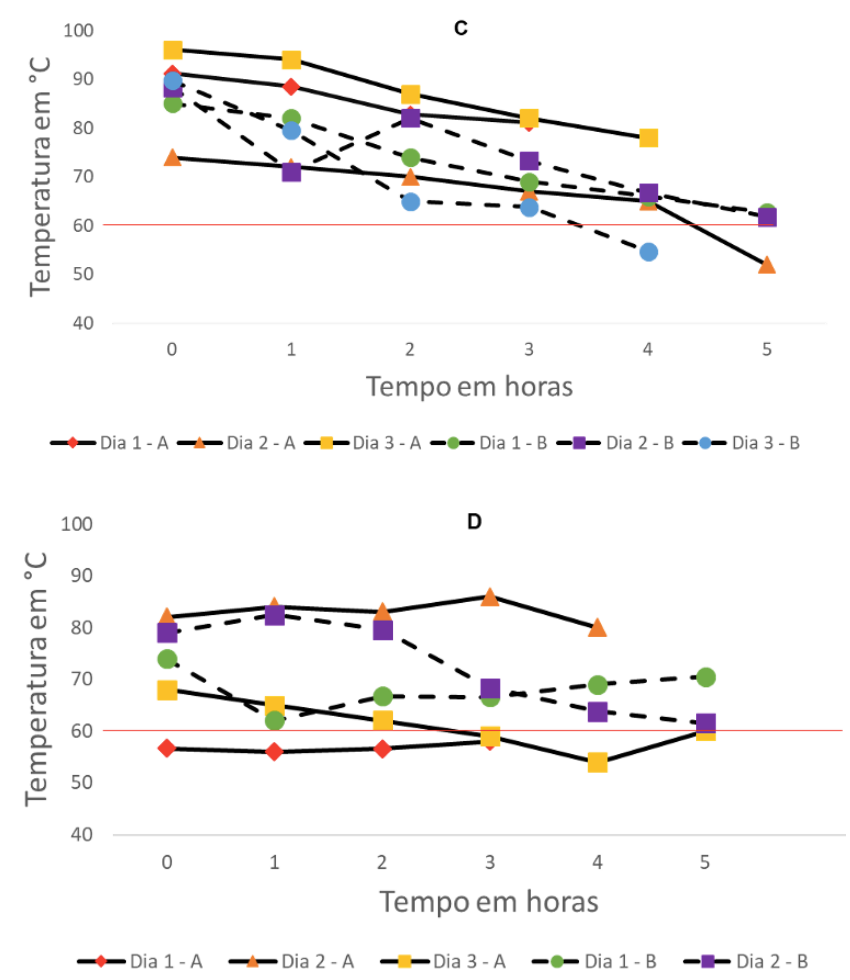

Em relação às preparações do prato principal, 66,6\% estavam adequadas em relação ao binômio tempo e temperatura (Figura 2A). Apesar da adequação, é possível visualizar uma redução gradual das temperaturas dessas preparações em todos os dias. Dentre as preparações quentes avaliadas, as que apresentaram os piores resultados foram as opções vegetarianas, uma vez que nenhuma preparação se encontrou dentro dos parâmetros do binômio tempo e temperatura recomendados (Figura 2B).

Figura 2. Binômio tempo e temperatura de preparações quentes na unidade A e unidade B. (A) Prato Principal; (B) Opção Vegetariana

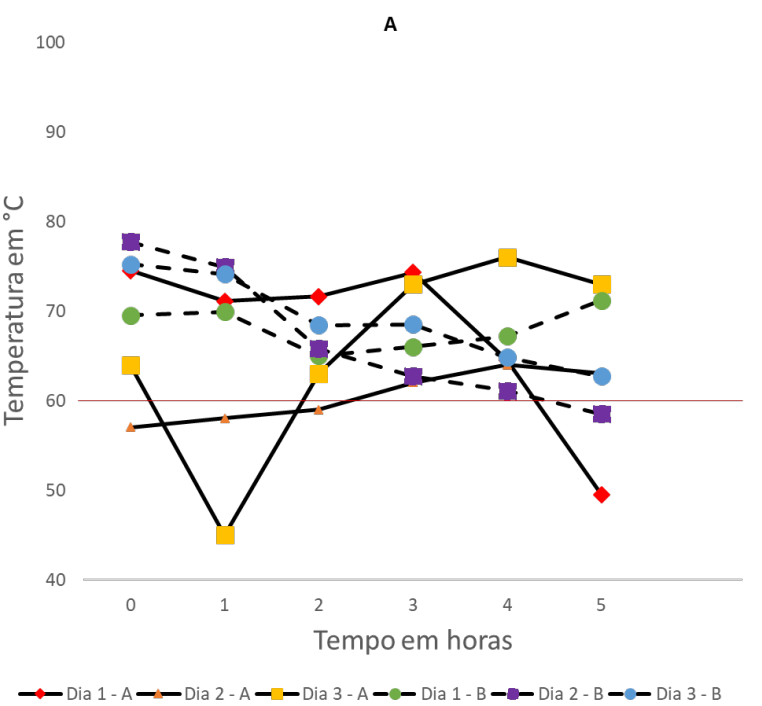




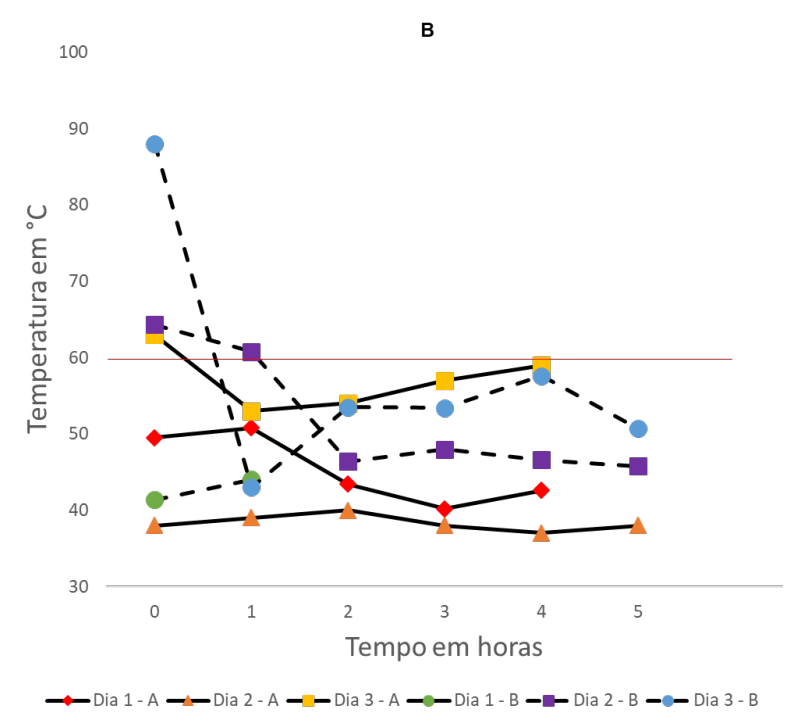

\section{Preparações Frias}

Foram analisadas 18 preparações frias, sendo seis saladas de folhosos, seis de legumes crus e seis de legumes cozidos. Quanto às saladas de legumes cozidos (Figura 3A) observou-se que no tempo zero (0) a temperatura inicial de todas as preparações estava acima de $10^{\circ} \mathrm{C}$. No tempo 2, que seria o tempo limite para que a redução $10^{\circ} \mathrm{C}$ estivesse finalizada, nenhuma preparação se encontrou abaixo dessa temperatura, estando inadequadas para consumo por não atenderem ao binômio tempo e temperatura. Destaca-se que até a última aferição ( 5 horas após o tempo 0), apenas uma salada esteve abaixo $\mathrm{de}^{\circ} 0^{\circ} \mathrm{C}$, conseguindo atingir a temperatura 4 horas após o preparo. Evidentemente, nenhuma salada de legumes cozidos foi armazenada a temperatura recomendada após a redução, que seria a $4^{\circ} \mathrm{C}$.

Apesar da inadequação de todas as preparações de saladas de legumes cozidos (Figura 3A), observa-se grande variação na temperatura inicial das preparações. As preparações que apresentaram menores temperaturas no tempo Zero (0) (dia 2A, dia $1 \mathrm{~B}$ e $2 \mathrm{~B}$ ) foram preparações com ingredientes cozidos na noite anterior ao consumo, permanecendo em geladeiras durante a noite.

A análise das temperaturas das saladas de folhosos (Figura 3B) possibilitou observar que nenhuma delas esteve abaixo de $10^{\circ} \mathrm{C}$. Uma preparação (dia $3 \mathrm{~A}$ ) esteve entre $10^{\circ} \mathrm{C}$ e $21^{\circ} \mathrm{C}$, podendo ser armazenada, distribuída e consumida por até 2 horas, mas permaneceu armazenada durante 5 horas, portanto estava inadequada para consumo por não respeitar o tempo do binômio e indica falha no monitoramento de temperatura dessas preparações. O restante, 83,0\% das saladas de folhosos, encontrava-se acima de $21^{\circ} \mathrm{C}$, estando inadequadas para consumo. 
Figura 3 - Binômio tempo e temperatura de preparações frias na unidade A e unidade B. (A) Salada de Legumes Cozidos; (B) Salada de Folhosos; (C) Salada de Legumes Crus.
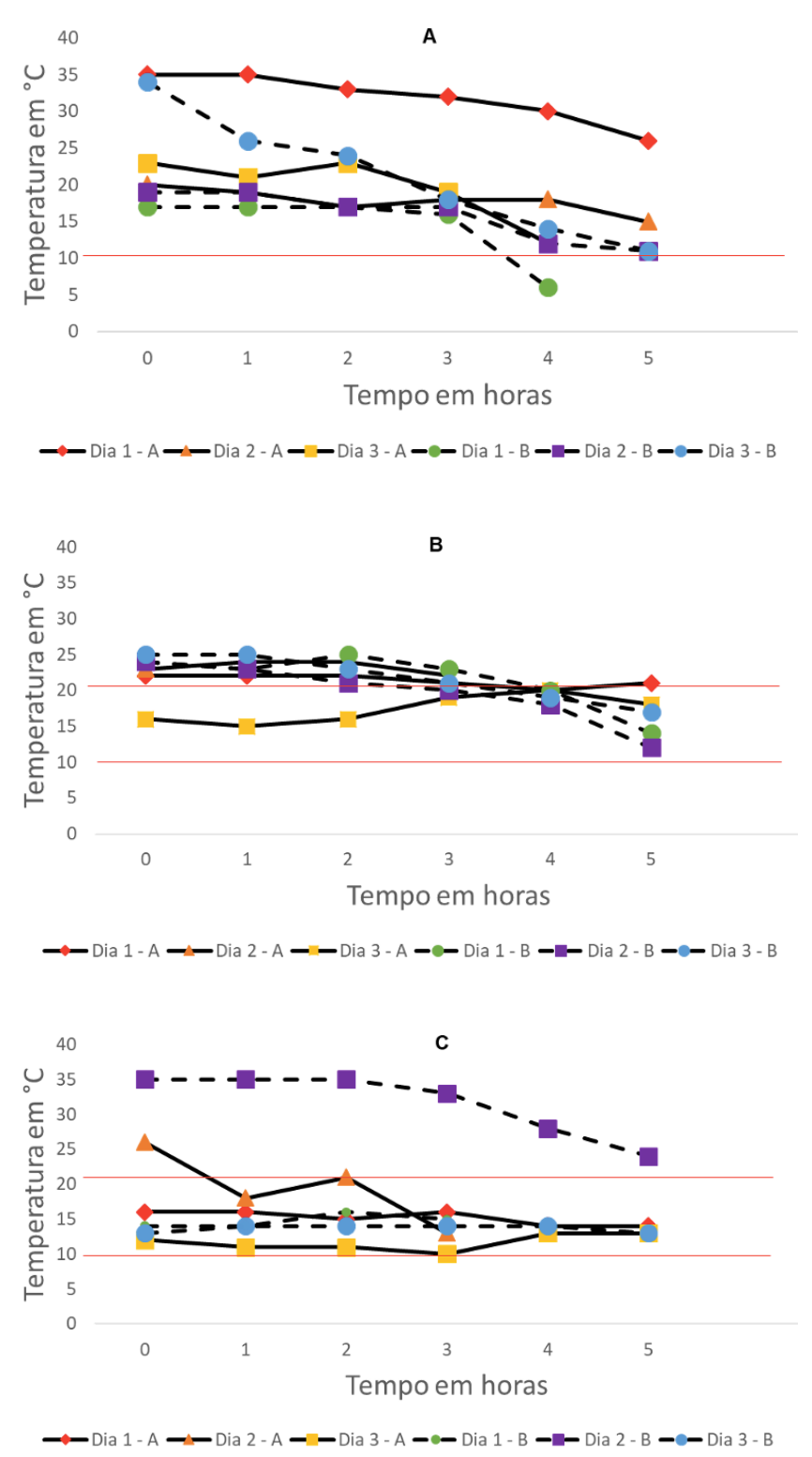

Em relação à salada de legumes crus (Figura $2 \mathrm{C}$ ), $66,6 \%$ estiveram entre $10^{\circ} \mathrm{C} \mathrm{e} 21^{\circ} \mathrm{C}$, podendo ser armazenadas, distribuídas e consumidas em até 2 horas. As preparações do dia $1 \mathrm{~B}$ e 3B foram distribuídas após 3 horas e as preparações do dia $1 \mathrm{~A}$ e $3 \mathrm{~A}$ estiveram armazenadas até a última aferição, 5 horas após a primeira medição. Sendo assim, nenhuma destas preparações estava adequada para consumo em função do tempo em que ficaram à espera para a distribuição. $O$ restante das saladas de legumes crus $(33,3 \%)$ apresentou temperatura inicial acima de $21^{\circ} \mathrm{C}$, ou seja, também inadequadas para consumo devido a temperatura. 


\section{DISCUSSÃO}

\section{Preparações Quentes}

Os resultados encontrados em relação às preparações de arroz foram semelhantes aos observados por Borges et al. $^{20}$, onde $100,0 \%$ das preparações de arroz respeitaram o binômio tempo e temperatura. Entretanto, Oliveira et al. ${ }^{19}$, não encontraram nenhuma preparação de arroz acima de $60^{\circ} \mathrm{C}$ em restaurantes do tipo autosserviço da capital mineira.

A inadequação encontrada nas preparações de arroz se concentrou no dia 3 da unidade A (Figura 1 A e B). Esse arroz era uma sobra do jantar do dia anterior, que foi reaquecida em um forno e acondicionada no carro térmico à espera para ser servida no almoço. Tal situação indica que a sobras do arroz branco e integral não foram reaquecidas de maneira adequada, dessa forma, estavam inadequadas para consumo independente do respeito ou não ao binômio tempo e temperatura. Para o reaproveitamento seguro de sobras, as preparações devem atingir $74^{\circ} \mathrm{C}$ no seu interior ou combinações conhecidas de tempo e temperatura, como: $70^{\circ} \mathrm{C}$ por 2 minutos ou $65^{\circ} \mathrm{C}$ por 15 minutos no centro geométrico do alimento ${ }^{21}$.

Estes resultados encontrados referentes ao arroz, podem indicar ausência de mecanismos de controle da temperatura do armazenamento até a distribuição, além de equipamentos de aquecimento inadequados ${ }^{22}$. Segundo Pereira ${ }^{23}$, um dos microorganismos que mais contamina cereais é a bactéria Bacillus cereus, que se multiplica bem entre $19^{\circ} \mathrm{C}$ e $48^{\circ} \mathrm{C}^{32}$, temperaturas próximas às observadas nas preparações inadequadas.

A adequação das preparações de feijão também foi observada por Borges et al. ${ }^{20}$. Em discordância, Oliveira et al. ${ }^{19}$ encontraram $98,7 \%$ das preparações abaixo de $60^{\circ} \mathrm{C}$. As preparações de feijão possuem alto teor de líquido, o que favorece as altas temperaturas e a manutenção das mesmas ${ }^{12,24}$. No presente estudo, a preparação feijão foi sempre a última a ser preparada, indicando um tempo menor de armazenamento no carro térmico aquecido, quando comparado com as outras preparações, o que pode, também, ter influenciado na adequação do binômio.

Apesar da adequação ao binômio tempo e temperatura (Figura 1C) observou-se que todas as preparações de feijão sofreram reduções progressivas nas temperaturas. Isso pode ter ocorrido por uma situação observada em todos os dias de coleta de 
dados, que foi o acondicionamento das GN na parte mais baixa do carro térmico aquecido, sendo mais distante da resistência do equipamento, que é a região mais quente. O segundo ponto diz respeito à quantidade da preparação na $\mathrm{GN}$, sendo comum a retirada gradual do feijão da GN, mas não a GN em si. Essa redução pode ter facilitado a perda de calor pela maior circulação de ar. Tal situação pode ser evitada com o monitoramento constante das preparações e do volume da preparação nas GN.

Em relação às guarnições, Marinho, Souza e Ramos²4 relatam que, geralmente, são preparações variadas, podendo favorecer ou não a manutenção da temperatura, dependendo do teor de água que as compõe. A preparação que apresentou temperatura inicial abaixo de $60^{\circ} \mathrm{C}$ apresentava baixo teor de água, a farofa.

Devido à variação das preparações de guarnições, Oliveira et al. ${ }^{19}$, corroborando os resultados do presente estudo, encontraram 96,0\% das guarnições avaliadas em restaurantes comerciais abaixo da recomendação de $60^{\circ} \mathrm{C}$. O monitoramento da temperatura de preparações como essa, em diferentes momentos, é de suma importância, para que sejam tomadas medidas corretivas necessárias, como o reaquecimento, a fim de garantir que estejam constantemente dentro da faixa recomendada.

Já em relação às preparações de prato principal, segundo Fuhr e Tasca ${ }^{25}$, as preparações cárneas tendem a perder temperatura após o preparo devido à baixa quantidade de água e maior superfície de contato. De maneira mais proeminente, os dias 1,2 e 3 da unidade A demonstraram bem essa característica, pois ambas as preparações não possuíam molhos e eram bifes ou carne em pedaço. $O$ decréscimo mais acentuado de temperatura do dia 1 na unidade A aconteceu justamente pela diminuição de alimento no GN e aumento da área de contato.

Os dias 2 e 3 da unidade A (Figura 2A) apresentaram temperaturas oscilantes, inclusive com perda de temperatura e recuperação da mesma posteriormente. $\mathrm{Na}$ rotina das duas unidades em estudo, já havia sido observada essa redução de temperatura dessas preparações, e como forma de postergá-la ou evitá-la, o procedimento adotado foi alocar as GN que contém o prato principal na parte superior do carro térmico, mantendo-as mais próximas à extremidade superior do carro, onde fica localizada a resistência do equipamento e, portanto, mais quente. Tal estratégia pode explicar o aumento de temperatura da preparação nesses dias. 
Importante destacar que o reaquecimento de preparações não é um procedimento frequentemente adotado nas unidades em estudo.

Em discordância aos resultados encontrados, Oliveira et al..$^{19}$ encontraram menos de $15,0 \%$ das preparações de prato principal acima de $60^{\circ} \mathrm{C}$. A Salmonella sp é um dos micro-organismos que mais comumente contaminam produtos cárneos (base do prato principal $)^{26}$. Sua temperatura ótima de crescimento é entre $35^{\circ} \mathrm{C}$ a $37^{\circ} \mathrm{C}^{32}$, o que justifica o frequente monitoramento dessas preparações, evitando que a temperatura sofra reduções até esses valores. A contaminação por essa bactéria pode causar dores abdominais, cefaleia, náusea, vômito, febre e diarreia ${ }^{23}$. A Salmonella $s p$. é um dos principais micro-organismos causadores de DVA, tendo alta adaptabilidade e virulência ${ }^{27}$.

Em relação às preparações de opção vegetariana, Nascimento et al. ${ }^{28}$ também encontraram resultados consideráveis de inadequação. De três restaurantes avaliados, apenas um estava de acordo em todas as aferições realizadas. Em contrapartida, Borges et al. ${ }^{20}$ encontraram percentual alto de adequação ao binômio (97,0\%). Os autores atribuíram esse achado ao fato de a opção vegetariana no restaurante em questão ser finalizada próximo ao momento da distribuição e ser mantida em fornos aquecidos.

No restaurante universitário do presente estudo, a opção vegetariana era preparada para as duas unidades ao mesmo tempo, porém, devido à necessidade de transporte para a unidade $\mathrm{B}$, a alocação da preparação nas GN para a unidade A acontecia posteriormente, o que pode ter contribuído para a inadequação da temperatura desde a primeira aferição das preparações para essa unidade (Figura 2B).

A maioria das preparações vegetarianas enviadas para a unidade B apresentou temperatura adequada, porém todas perderam temperatura muito rapidamente, ficando abaixo de $60^{\circ} \mathrm{C}$ na segunda ou terceira aferição (Figura 2B). Duas possibilidades podem ser responsáveis por essa redução rápida, a primeira é que na UAN em estudo, devido ao menor volume de preparações vegetarianas servidas, elas eram preparadas em quantidades reduzidas e armazenadas em GN pequenas. Apesar da escolha por um GN pequeno, a circulação de ar dentro dela é maior devido à pequena quantidade da preparação, o que favorece o seu resfriamento de maneira mais rápida. A segunda possibilidade é a de que no transporte da unidade A para a unidade $B$, o carro térmico aquecido ficava desligado durante o trajeto o que pode ter 
colaborado para a redução da temperatura das preparações vegetarianas, que já estariam com temperaturas pouco adequadas.

Além disso, as preparações oferecidas pelas unidades são, em grande maioria, sem caldos ou molhos, com frequente utilização de ovos cozidos e omeletes, favorecendo a perda de calor. As possibilidades para melhora da temperatura dessas preparações incluem o preparo conforme demanda ao longo da distribuição, a substituição de receitas que possuam mais facilidade de reter calor e, principalmente, a implantação de procedimentos para monitoramento das temperaturas e estabelecimento de ações corretivas padronizadas a serem adotadas em caso de inadequação de temperatura das opções vegetarianas.

\section{Preparações Frias}

As temperaturas de armazenamento que tangem as saladas de legumes cozidos são necessárias pois, por mais que o vegetal tenha sofrido cocção, o efeito do calor não é permanente, tornando o alimento passível de recontaminação ou mesmo de multiplicação de micro-organismos residuais ${ }^{29}$. Dessa forma, o resfriamento lento da preparação, observado no presente estudo, a coloca em uma faixa de temperatura propícia para contaminação por Staphylococcus spp, uma das intoxicações mais frequentes no mundo ${ }^{26}$. O crescimento deste microrganismo acontece entre $7^{\circ} \mathrm{C} \mathrm{e}$ $46^{\circ} \mathrm{C}^{30}$ e a contaminação dos alimentos ocorre normalmente no momento da manipulação direta por indivíduos portadores assintomáticos ou por indivíduos que possuem algum tipo de infecção, geralmente cutânea ${ }^{26}$.

Para Bozatski, Moura e Novello ${ }^{31}$, a inadequação nas temperaturas de saladas cozidas se deve ao fato de os ingredientes serem cozidos muito próximos ao horário de distribuição, não sendo levados para a refrigeração antes da montagem da salada. Dessa forma, uma maneira de melhorar a temperatura dessas saladas é realizar a hidratação/cozimento dos ingredientes no dia/noite anterior e o armazenamento das mesmas a $5^{\circ} \mathrm{C}$. Ainda em relação às saladas de legumes cozidos, algumas preparações tiveram reduções bruscas de temperatura, como nos dias 1B e 3B (Figura 3A). Isso pode ter ocorrido devido à retirada gradual da preparação do $\mathrm{GN}$, o que aumenta o espaço para a circulação de ar e consequente resfriamento.

Entre as saladas de folhosos, Alves e Ueno ${ }^{18}$ indicam que, dentre as principais causas para a prevalência encontrada de saladas acima de $21^{\circ} \mathrm{C}$ estão a falta de 
equipamentos adequados de refrigeração e a falta de conscientização dos manipuladores em realizar a refrigeração de maneira correta. Também pode ocorrer o armazenamento inadequado das preparações frias, antes da produção. Em muitos casos, os equipamentos estão adequados, porém em temperaturas incorretas. Tal situação foi observada no presente estudo, uma vez que todas as saladas de folhosos atingiram a faixa de $10^{\circ} \mathrm{C}$ a $21^{\circ} \mathrm{C}$ após algumas horas de armazenamento (Figura $2 \mathrm{~B}$ ).

As preparações de saladas de legumes crus que estavam dentro da faixa de temperatura permitida $(66,6 \%)$ foram preparadas com ingredientes prépreparados na noite anterior ao dia que foram utilizadas, passando a noite no refrigerador o que, possivelmente, contribuiu para essa adequação. As duas preparações acima de $21^{\circ} \mathrm{C}$ continham ingredientes hidratados com água quente, $\mathrm{o}$ que eleva a temperatura da preparação como um todo. Essas características reforçam o que afirmaram Alves e Ueno ${ }^{18}$ e Bozatski, Moura e Novello ${ }^{31}$, sobre a necessidade de antecedência no preparo e o armazenamento adequado das preparações frias que compõem o cardápio.

Considerando que as preparações frias podem ser armazenadas, distribuídas e consumidas por no máximo 4 horas se estiverem em temperaturas inferiores a $10^{\circ} \mathrm{C}$ e, quando estiverem entre 10 e $21^{\circ} \mathrm{C}$, só poderão permanecer na distribuição por 2 horas, Sousa, Pontes e Nascimento ${ }^{17}$ encontraram todas as saladas durante a distribuição em um restaurante universitário inadequadas para consumo.

Em outro estudo, Ricardo, Morais e Carvalho ${ }^{12}$ encontraram todas as temperaturas das saladas avaliadas em restaurantes comerciais de um município goiano em não conformidade com o binômio tempo e temperatura. Borges et al. ${ }^{20}$, ao aferirem as temperaturas de preparações frias pós-preparo, durante o armazenamento e na distribuição, em um restaurante comercial, encontraram $22,0 \%$ delas entre $10^{\circ} \mathrm{C}$ e $21^{\circ} \mathrm{C}$ e as classificaram como adequadas para consumo por adotarem que as mesmas podem ser distribuídas e consumidas por no máximo três horas.

Ao analisarem a temperatura de saladas de restaurantes comerciais de uma cidade paulista, Alves e Ueno $^{18}$ identificaram que $53,1 \%$ das saladas no momento da distribuição estavam acima de $21^{\circ} \mathrm{C}$. Da mesma forma, Oliveira et al..$^{19}$, ao aferirem as temperaturas de diferentes alimentos em diversos restaurantes da capital mineira, encontraram $35,5 \%$ das saladas de legumes cruas acima de $21^{\circ} \mathrm{C}$. O percentual de 
salada de folhosos acima de $21^{\circ} \mathrm{C}$ encontrado por esses autores também foi alto $(50,0 \%)$, porém inferiores aos encontrados no presente estudo (83,0\%).

A análise dos resultados desse estudo em relação às saladas cruas e os achados na literatura indicam ser recorrente a dificuldade desse tipo de preparação atingir a temperatura adequada e a inoperância dos gestores para controlar o tempo para consumo dessas preparações, quando em temperaturas inadequadas.

O fator mais preocupante é que entre $7^{\circ} \mathrm{C}$ e $48^{\circ} \mathrm{C}$ a Salmonella sp., uma das principais bactérias que contamina alimentos de origem vegetal, pode se desenvolver e vir a infectar indivíduos que podem sofrer com cólicas abdominais, náuseas e febre ${ }^{32}$. Outros dois micro-organismos comuns em hortaliças são a Listeria monocytogenes e a Escherichia coli ${ }^{32}$. A primeira possui temperatura ideal para reprodução entre $1^{\circ} \mathrm{C} \mathrm{e}$ $45^{\circ} \mathrm{C}^{27}$ e pode causar náusea, vômito e até mesmo evoluir para meningite ${ }^{23}$ e a segunda possui a temperatura de crescimento entre $8^{\circ} \mathrm{C}$ e $48^{\circ} \mathrm{C}^{34}$ e pode causar diarreia, fortes cólicas abdominais e, em alguns casos febre ${ }^{33}$. A ampla faixa de temperatura de crescimento dessas bactérias indica a necessidade de controle rigoroso da temperatura e tempo de armazenamento e exposição para consumo, conforme preconizado pela legislação.

Alguns autores ${ }^{19,35}$ sugerem alternativas para adequação das temperaturas das preparações servidas frias como, a redução da quantidade de alimentos porcionados nos GN, uma vez que o excesso de alimentos pode dificultar seu resfriamento e a utilização de banho de gelo ou de um equipamento específico para resfriamento, como o resfriador, que pode proporcionar o resfriamento mais rápido das preparações frias. Em geral, o resfriador pode reduzir temperaturas de $90^{\circ} \mathrm{C}$ a $3^{\circ} \mathrm{C}$ em até 90 minutos, provocando um resfriamento rápido do alimento para uma faixa segura de temperatura ${ }^{36}$.

Outra alternativa que se apresenta como potencializadora da manutenção das saladas na temperatura adequada é a utilização de hortaliças minimamente processadas. Com a adoção delas em detrimento às in natura, o tempo gasto no prépreparo é quase inexistente e por isso, há um tempo maior entre o preparo da salada e a sua distribuição, aumentando a possibilidade de seu resfriamento ser mais eficiente. Entretanto, os custos das hortaliças minimamente processadas são mais elevados que os produtos in natura, sendo necessária uma avaliação do custobenefício desses alimentos, além de aspectos como sazonalidade, disponibilidade de 
fornecedor, oferta e procura dos alimentos, número de colaboradores e disponibilidade de equipamentos, antes da sua adoção em uma UAN37.

\section{CONCLUSÃO}

Foi possível constatar que as preparações frias à espera para distribuição apresentaram um alto percentual de inadequação do binômio tempo e temperatura. Em compensação, esse binômio se apresentou adequado para a maior parte das preparações quentes analisadas, com exceção das servidas como opção vegetariana e de algumas servidas como guarnição.

Por se tratar de um cuidado fundamental para garantir a segurança dos alimentos oferecidos aos clientes, a definição de procedimentos de controle e monitoramento da temperatura dos alimentos servidos em UAN, especificamente daqueles à espera para distribuição, deve ser compreendido como urgente e fundamental entre os nutricionistas e gerentes de serviços de alimentação. Tal cuidado, além de trazer benefícios para o cliente, possibilita a adequação à legislação vigente e uma maior longevidade do serviço de alimentação, em um mercado altamente competitivo.

Sugere-se que mais estudos que investiguem o binômio tempo e temperatura de preparações à espera para distribuição sejam realizados. Em grande parte, esse período entre a finalização da preparação e o momento em que será servida ao comensal é negligenciado pelos estudos, entretanto, se não for devidamente monitorado pode se constituir uma importante oportunidade de proliferação de micro-organismos patogênicos, colocando em risco a saúde dos consumidores.

\section{REFERÊNCIAS}

1. Vasconcelos NB. Programa nacional de assistência estudantil: Uma análise da evolução da assistência estudantil ao longo da história da educação superior no Brasil. Ens Em-Rev. 2010;17(2):599-616.

2. Rabelo NML, Alves TCU. Avaliação do percentual de resto-ingestão e sobra alimentar em uma unidade de alimentação e nutrição institucional. R. bras. Tecnol. Agroindustr. 2016;10(1):2039-52.

3. Moreira FJJ, Pafiadache C, Loose LH, Piaia R, Scher VT, Peripolli A, Palm B. Satisfação dos usuários do restaurante universitário da universidade federal de Santa Maria: Uma análise descritiva. Soc e Hum. 2015;28(2):83-108.

4. Constancio MB, Akustu, RCCA, Silva ICR, Camargo EB. Revisão da Literatura Alimentação Fora do Lar e os Desafios das Boas Práticas para a produção de alimentos de qualidade em Unidades de Alimentação e Nutrição - UAN. Acta de Cien e Saú. 2016;5(2):130-143. 
5. Rodrigues KL, Moreira NA, Almeida ATS, Chiocchetta D, Rodrigues MJ, Brod CS, Carvalhal JB, Guimarães JA. Intoxicação estafilocócica em restaurante institucional. Ciência Rural, 2004;34(1).

6. Passos EC, Almeida CS, Rosa JP, Rozman LM, Mello ARP, Souza CV, Paschoal RC, Tavares M. Surto de toxinfecção alimentar em funcionários de uma empreiteira da construção civil no município de Cubatão, São Paulo/Brasil. Rev. Inst. Adolfo Lutz, 2008;67(3):237-240.

7. Ministério da Saúde (BR), Secretaria de Vigilância em Saúde. Surtos de Doenças Transmitidas por Alimentos no Brasil. Brasília (DF); 2018.

8. FAO/WHO Food Standards. Codex Alimentarius [internet]. 2003 [acesso em 10 set 2018]. Disponível em:

http://www.actionlive.pt/docs/actionalimentar/codex_alimentarius_VersaoPor tuguesa_2003.pdf

9. Trindade MA, Silva G, Paula ESM. Manual de Boas Práticas de Fabricação: Treinamento in loco sobre higiene e conservação de alimentos para ambulantes de lanchonetes [internet]. São Paulo; 2010 [acesso em 10 set 2018]. Disponível em: https://www.usp.br/alimentoseguro/manual_bpf.htm

10. Braga AC, Pereira TL, Andrade PP. Avaliação de Restaurante Universitário por Meio de Indicadores de Qualidade. Des em quest. 2015;13(30):306-26.

11. Silva RA. Ciência do alimento: contaminação, manipulação e Conservação dos alimentos [trabalho de conclusão de curso]. Medianeira: Universidade Tecnológica Federal do Paraná - Campus Medianeira; 2012.

12. Ricardo FO, Morais MP, Carvalho ACMS. Controle de tempo e temperatura na produção de refeições de restaurantes comerciais na cidade de Goiânia-GO. Demetra. 2012;7(2):85-96.

13. Guerra AF. Fatores do crescimento microbiano. $1^{\text {a }}$ Edição. Rio de Janeiro: Valença; 2016.

14. Madigan MT, Martinko JM, Bender KS, Buckley DH, Stahl DA. Microbiologia de Brock. $14^{\mathrm{a}}$ Edição. Porto Alegre. Artmed; 2016.

15. Brasil. Resolução RDC $n^{\circ} 216$, de 15 de setembro de 2004. Dispõe sobre Regulamento Técnico de Boas Práticas para Serviços de Alimentação. Portal da Legislação: Agência Nacional de Vigilância Sanitária. 2004. Disponível em: http://portal.anvisa.gov.br/documents/33916/388704/RESOLU\%25C3\%2587\%2 $5 \mathrm{C} 3 \% 2583 \mathrm{O}-$ RDC\%2BN\%2B216\%2BDE\%2B15\%2BDE\%2BSETEMBRO\%2BDE\%2B2004.pdf/2 3701496-925d-4d4d-99aa-9d479b316c4b

16. São Paulo. Portaria CVS 5, de 09 de abril de 2013. Aprova o regulamento técnico sobre boas práticas para estabelecimentos comerciais de alimentos e para serviços de alimentação, e o roteiro de inspeção, anexo. Portal da Legislação: Centro de Vigilância Sanitária do Estado de São Paulo. 2013. Disponível em: http://www.cvs.saude.sp.gov.br/up/PORTARIA\%20CVS-5_090413.pdf

17. Sousa FS, Pontes CR, Nascimento LA. Temperatura de saladas transportadas servidas em um restaurante universitário. Nutrivisa - Rev de Nutri e Vig em Saúde. 2017;13(4):13-20.

18. Alves MG, Ueno M. Restaurantes self-service: segurança e qualidade sanitária dos alimentos servidos. Rev. Nutr. 2010;23(4):573-80. 
19. Oliveira LC, Flores RR, Amorim MMA, Ferreira CC, Amaral DA. Avaliação das temperaturas das preparações dos restaurantes self service do hipercentro de Belo Horizonte/MG. HU Revis. 2012;38(3):167-173.

20. Borges NR, Moura BA, Vieira CFS, Santos DM, Almeida LJ, Zuniga ADG. Avaliação do binômio tempo-temperatura das refeições de um restaurante na cidade de Palmas - Tocantins. Rev Desafios. 2016;3(2):90-8.

21. Marques ML, Silva EA. Manual ABERC de Práticas de Elaboração e Serviços de Refeições para Coletividades. 11ª Edição. São Paulo: ABERC; 2015.

22. Monteiro MAM, Ribeiro RC, Fernandes BDA, Sousa JF, Santos LM. Controle das temperaturas de armazenamento e de distribuição de alimentos em restaurantes comerciais de uma instituição pública de ensino. Demetra. 2014;9(1):99-106.

23. Pereira LR. Análise de perigos e pontos críticos de controle na produção de refeições industriais [dissertação]. Rio Grande: Fundação Universidade Federal do Rio Grande; 2007.

24. Marinho CB, Souza CS, Ramos SA. Avaliação do binômio tempo-temperatura de refeições transportadas. e-Scientia.2009;2(1):1-11.

25. Fuhr AL, Tasca CG. Monitoramento do binômio tempo e temperatura de refeições transportadas para trabalhadores. Nutrição Brasil. 2017;16(6):365-372.

26. Oliveira JJ. Surtos alimentares de origem bacteriana: uma revisão [dissertação]. Goiânia (GO): Escola de Veterinária e Zootecnia, Universidade Federal de Goiás; 2012.

27. Nascimento IR, Sena TL. Doenças veiculadas por alimentos: estudo da qualidade microbiológica de amostras de leite, ovos, carnes bovina e de frango encontradas em algumas feiras e açougues no distrito federal [relatório final de pesquisa de Iniciação Científica]. Brasília: Centro Universitário de Brasília UniCEUB; 2016.

28. Nascimento LA, Pontes CR, Sousa FS, Morais MR, Queiroz AA. Binômio tempo e temperatura de preparações em serviço de alimentação transportada. Nutrivisa - Rev de Nutri e Vig em Saúde. 2017;3(3):112-20.

29. Penedo AO, Jesus RB, Silva SCF, Monteiro MAM, Ribeiro RC. Avaliação das temperaturas dos alimentos durante o preparo e distribuição em restaurantes comerciais de Belo Horizonte - MG. Demetra. 2015;10(2):429-40.

30. Autoridade de Segurança Alimentar e Económica. Staphylococcus aureus [internet]. Portugal: Escola Superior de Biotecnologia, Universidade Católica. Disponível em: https://www.asae.gov.pt/seguranca-alimentar/riscosbiologicos/staphylococcus-aureus.aspx.

31. Bozatski LC, Moura PN, Novello D. Análise do binômio tempo x temperatura na distribuição de alimentos em unidades de alimentação e nutrição comerciais do município de Guarapuava, Paraná [trabalho de conclusão de curso]. Guarapuava: UNICENTRO; 2011.

32. Carvalho IT. Microbiologia dos alimentos. Recife: EDUFRPE; 2010.

33. Boston Public Health Commission. E. coli (Escherichia coli) [internet]. Boston: BPHC; June 2014. Disponível em: http://www.bphc.org/whatwedo/infectiousdiseases/Infectious-Diseases-A-toZ/Documents/Fact\%20Sheet\%20Languages/E.coli/Portuguese.pdf 
34. Autoridade de Segurança Alimentar e Económica. Escherichia coli [internet]. Portugal: Escola Superior de Biotecnologia, Universidade Católica. Disponível em: http://www.asae.gov.pt/?cn=541054135465AAAAAAAAAAAA

35. Artur, PO. Aplicação do binômio tempo/temperatura em alimentos [trabalho de conclusão de curso]. Brasília: Universidade de Brasília; 2004.

36. Calheiros KO. Avaliação de implementação do sistema cook-chill em unidade de alimentação e nutrição - UAN [tese]. Piracicaba: Universidade de São Paulo; 2016.

37. Degiovanni GC, Japur CC, Sanches APLM, Mattos CHPS, Martins LS, Reis CV, Vieira MNCM. Hortaliças in natura ou minimamente processadas em unidades de alimentação e nutrição: quais aspectos devem ser considerados na sua aquisição? Rev. Nutr. 2010;23(5):813-22.

Submissão: 09/02/2020

Aprovação: 13/10/2020 